American Journal of Applied Sciences 2 (10): 2076-2078, 2006

ISSN 1546-9239

(C) 2006 Science Publications

\title{
Electrical Sterilization of Juice by Discharged HV Impulse Waveform
}

\author{
Hee-Kyu Lee \\ Department of Digital and Industrial Electronic Engineering \\ Bucheon College, 424 Simgok-dong, Wonmi-ku, Bucheon 421-735, South Korea
}

\begin{abstract}
In the sterilization system by using HV impulse waveform, apple juice was sterilized with HV discharged oscillatory decay waveform. The optimal condition of impulse waveform for electrical sterilization has presented the excellent condition at $40 \mathrm{kV} \mathrm{cm}^{-1}, 4 \mathrm{mH}$ and over. The characteristics of this waveform shows oscillatory decay waveform with multiple pulses. And this impulse waveform was more effective to kill S. Cervisiae than exponential decay waveform. S. Cervisiae to become musty and sour for apple juice was used as the sample. This apple juice has good effect of electrical sterilization because of higher conductivity than water. Therefore this experiment can be treated sterilization without loss of vitamin $\mathrm{C}$ and original taste or perfume to apple juice. As a result, it is found that apple juice can be sterilized on $40 \mathrm{kVcm}^{-1}, 4 \mathrm{mH}$ and over by using our designed $\mathrm{HV}$ impulse sterilizer.
\end{abstract}

Key words: Sterilization, Oscillatory decay, HV impulse, Saccharomyces cervisiae exponential decay

\section{INTRODUCTION}

Electrical sterilization of biological cells has the advantage of conventional, chemical or thermal sterilization and has been studied by many researchers. According to Sale and Hamilton, the condition of sterilization is determined by the product of the pulse length and number of pulses and by the field strength in the suspension ${ }^{[1-3]}$. RLC circuit with oscillating parameters, which consists of a capacitive energy storage source and a inductive pulse duration and a resistive cell suspension chamber has been widely used for a discharging network. RLC circuit shows multiple pulses(although oscillatory decaying) are available during the charging and discharging between capacitor and inductance with chamber containing cell suspension. Especially, according to our experiments results we think that this multiple pulse has the high efficiency for the same stored energy in capacitor whereas, conventional CR circuit has only single pulse is available by discharging energy stored in capacitor to treatment chamber containing cell suspension ${ }^{[4,5]}$. Therefore the RLC condition is considered one of the most important point to be investigated for electrical sterilization by HV impulse. The authors carried out an experiment to sterilize apple juice using our sterilizer consists of RLC network. Apple juice which is one of the popular juice with orange juice or grape juice in our country. But apple juice has the limited storage life which resulted from the store because of manufacturing without fired store process or because of being microorganism contaminated by manufacturing process. And especially, what we call S. Cervisiae well known to the general public as to acidify the apple juice possessed the characteristics of only well living in apple juice. So it is very important to sterilize the $S$. Cervisiae for the good quality of apple juice. Generally, in the manufacturing company, there make an attempt at improvement in the preservation of apple juice by means of heat treat. But sterilization by heating has the point at issue to be deteriorate the quality of apple juice because of oxidizing or resolving the ingredients of apple juice by heating and because of vitamin $\mathrm{C}$ degeneration, loss of original taste and perfume. Therefore this experiment can be treated sterilization without such a point at issue.

\section{MATERIALS AND METHODS}

Figure 1 shows schematic diagram of experimental apparatus. In pulse generator, $\mathrm{C}(=0.1 \mathrm{uF})$ of condenser was charged from dc high voltage source and discharge into the electrode (=Tank) by controller. In this case, the pulsed voltage was decayed by time constant (=CR). $\mathrm{R}$ and $\mathrm{C}$ are fixed, while only $\mathrm{L}$ value is changeable for good condition of oscillation decay. The diameter of treatment tank is $40 \mathrm{~cm}$ and height is $60 \mathrm{~cm}$. and the electrode's diameter is $20 \mathrm{~cm}$, and Gap distance of electrode in treatment tank is adjusted to $10 \mathrm{~cm}$. The pulse of applied electric field is $2 \mathrm{kVcm}^{-1}$ and the repetition rate of controller is operated as follows:

$\mathrm{T}=\mathrm{nt} ;(\mathrm{T}$; treatment time, $\mathrm{n}$; number of pulse, t: pulse width), $n=(f . V) / m(n$; number of pulse, f; number of frequency, $\mathrm{V}$; volume $(\mathrm{mL})$ of container, $\mathrm{m}$; flux $(\mathrm{mL} / \mathrm{s})$ ) and pulse width was 10us.

Corresponding Author: Hee-Kyu Lee, Professor, Department of Digital \& Industrial Electronic Engineering, Bucheon College, 424 Simgok-dong, Wonmi-ku, Bucheon 421-735, South Korea, Tel: (82)32-610-3261, Fax: (82)32-610-3236 


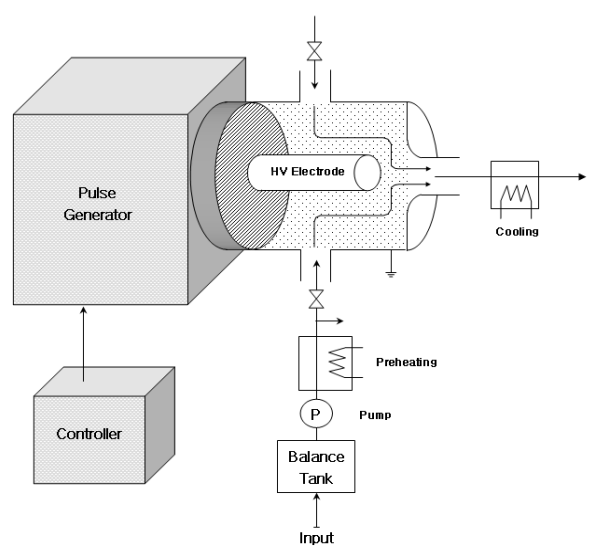

Fig. 1: Schematic diagram of HV impulse sterilizer

The S.Cervisiae is followed on the heels of apple juice to buy in market in order to be made $2.0 \times 10^{8}$ at initial number of cell. The sample in the shocked apple juice is diluted to $10^{-6}$ range. The $0.1 \mathrm{ml}$ of sample are transferred to the surfaces of Rogosa SL agar plates and spread over the surface of agar with a sterile glass rod. Then the plates are incubated at a temperature of $30^{\circ}$ for 5 days and the numbers of colonies are counted.

Therefore the influence of HV impulse on the S.Cervisiae has been measured as a survival ratio ( $\mathrm{S}=\mathrm{N} / \mathrm{No}$, where $\mathrm{N}$ and No are a number of active microbes per unit volume after and before the voltage treatment, respectively)

\section{RESULTS AND DISCUSSION}

In this experiments the energy stored in the capacitor $\left(1 / 2 \mathrm{CVo}^{2}\right)$ is used as the energy input to the suspension by one pulse. The energy input was $31.25 \mathrm{~J}$ at $\mathrm{Vo}=25 \mathrm{kV}$ and $80 \mathrm{~J}$ at $\mathrm{Vo}=40 \mathrm{kV}$. In the same condition Fig. 2 illustrates that the survivability decrease with the change in the pulsed number. Here, the inductance value used $4 \mathrm{mH}$. For example in case of $25 \mathrm{kV}$ the survivability decrease by 10 times of magnitude within the range of pulsed number 10 to 40 times. And in case of the same condition on 20 times, the survivability decrease by 10 times of magnitude within the range of voltage 10 to $40 \mathrm{kV}$. Therefore, the more pulsed number and electric field strength are increase, the more the survival ratio is decrease.

In Fig. 3 the survival ratio of S. Cervisiae is shown as function of the inductance value against electric field strength. Here, the number of applied pulses was 40 times. In case of $14 \mathrm{mH}$, the survivability decreases by ten millionth on $40 \mathrm{kV} \mathrm{cm}^{-1}$.

For $0 \mathrm{mH}$ a decrease of 4 times of magnitude takes place for $5 \mathrm{kV}$ to $40 \mathrm{kV}$. It is evident that the survivability decreases by 10 times of magnitude within the range of inductance 0 to $14 \mathrm{mH}$. But in case of $4 \mathrm{mH}$ and over, the survivability is shown to decrease of 15 times of magnitude than that of $0 \mathrm{mH}$. As shown in Fig. 3 and 4, it is found that electric field strength with

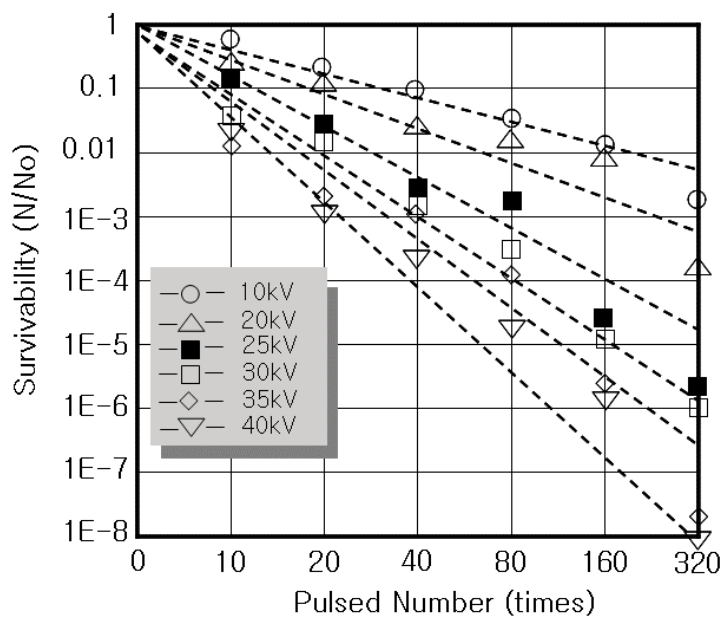

Fig. 2: Survivability on pulsed number against electric field strength

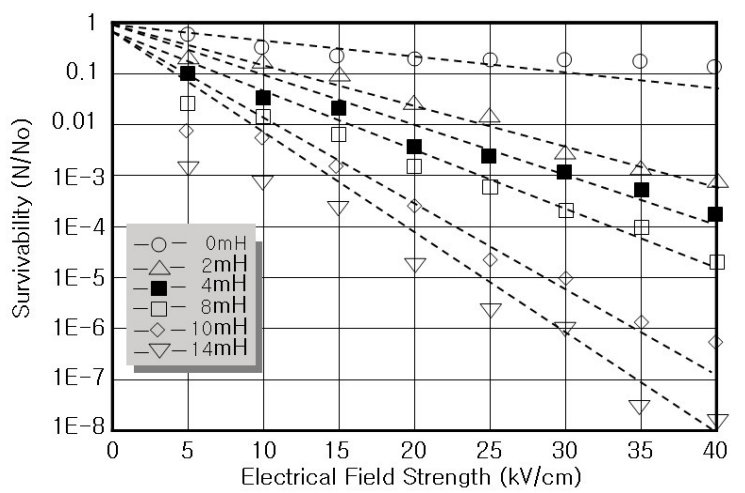

Fig. 3: Survivability on inductance value against electric field strength

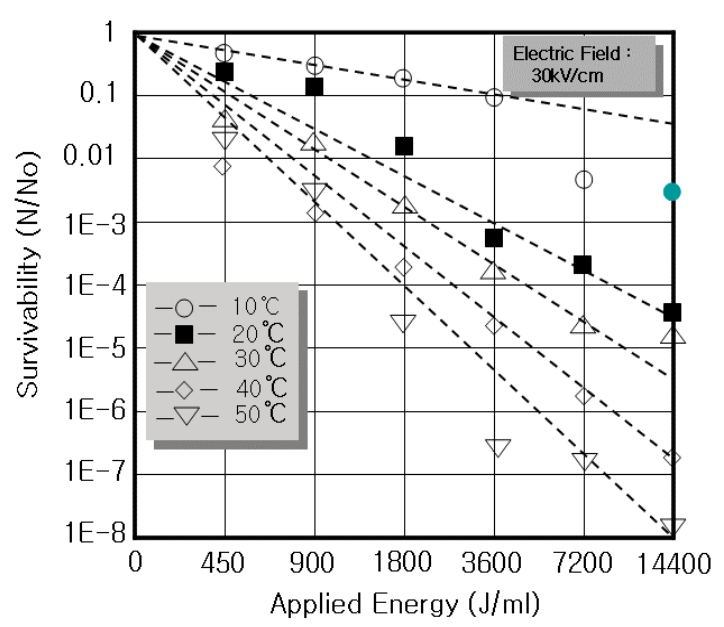

Fig. 4: Survivability on liquid temperature against applied energy

high $\mathrm{L}$ value has effect of sterilization on $S$. cervisiae.

And in Fig. 4 there can obtain the effect of full sterilization for $30 \mathrm{kVcm}^{-1}, 14400 \mathrm{~J} \mathrm{~mL} \mathrm{~m}^{-1}$ with the applied liquid temperature of $50^{\circ}$. And in case of $450 \mathrm{~J}$ $\mathrm{mL}^{-1}$, the survivability decrease by 80 times of 
magnitude within the range of liquid temperature 10 to $50^{\circ}$.

\section{CONCLUSION}

In this experiment, there can obtain the effect of sterilization, $99.9999 \%$ for electric field strength of $30 \mathrm{kV} \mathrm{cm}^{-1}$ and applied energy of $14400 \mathrm{~J} \mathrm{~mL}^{-1}$ with applied liquid temperature of $50^{\circ}$. It means that the sterilization of apple juice has out and out the best in parallel with electrical sterilization and low temperature sterilization processing. And finally, it is found that the survivability of $S$. Cervisiae being tested decreases with an increase in $\mathrm{L}$ value of $4 \mathrm{mH}$ and over.

\section{REFERENCES}

1. Zimmermann, U., 1986. Electrical breakdown, electropermealization and electrofusion. Rev. Physiol. Biochem. Pharmacol., Springer Verlag, 105: 175-265.

2. Pothakamury, U.R., A. Monsalve-gonzalez, G.V. Barbosa-Ca'novas and B.G. Swanson, 1994. Inactivation of Escherichia coli and Staphylococcus aureus in model foods by pulsed electric field technology. Food Preservation Proc., Natick, MA.
3. Mazurek, B. and P. Lubicki, 1995. Effect of short HV pulses on bacteria and fungi. Acryl IEEE Trans. on Dielectrics and Electrical Insulation, 2: 3.

4. Lee, H.K., J. Suehiro, M.H. So, M. Hara and D.C. Lee, 1997. Measurement of excellent condition to RLC parameter for electrical sterilization of Escherichia coli. Proc. of 5th Int'1 Conf. on Properties and Application of Dielectric Materials. 2: 1436-1439.

5. Lee, H.K., J. Suehiro, M.H. So, M. Hara and D.C. Lee, 2000. Energy efficiency improvement of electrical sterilization using oscillatory waveforms from a RLC discharging circuit. IEEE Trans. Dielectrics, El, 7: 872-874. 